\title{
Women in Oceanography A Web Site for Students, Teachers, Scientists, and the General Public
}

\author{
BY DEBORAH K. SMITH, EDWIN SCHIELE, AND LORI DOLBY
}

In 1999 as the millennium was drawing to a close, we decided that the time was right to introduce a new type of web site highlighting the contributions that women are making to marine science. program to create the web site, and in the winter of 2000, we launched Women in Oceanography (http://www.womenoceanographers.org). Five years later, the web site contains profiles of thirteen

\section{WWW.WOMENOCEANOGRAPHERS.ORG}

\section{...a web site highlighting the contributions}

\section{that women are making to marine science.}

We envisioned a web site where women considering careers in oceanography could read about the experiences of successful women and learn from their choices; that would convey the excitement of groundbreaking research in oceanography and serve as a resource for teachers, scientists, and the general public; and that would celebrate a group of remarkable women and bring a human face to those working in marine science.

In the fall of 1999, we received funding from the National Science Foundation's Awards to Facilitate Geoscience Education (AFGE) competitive grant (soon to be fourteen) diverse women, each with a unique story to tell. And it is still going strong.

As the web site has come together and evolved, we have found that it does more than celebrate these successful women and their achievements. It provides a realistic view of these women's professions and addresses the challenges they faced while pursuing their careers. The web site demonstrates that there are no typical scientists or career paths. With each profile, the authors and visitors have learned something new and have gained new perspectives on marine science. We have learned that although the women we profiled are united by their love of the ocean and by the drive and discipline needed to succeed, they have varied interests, have faced different challenges, and have made unique contributions to the study of oceanography. Throughout the web site, the concept stressed is that the work of these women represents pieces of a larger puzzle: each woman has contributed to our knowledge of Earth and its oceans.

\section{DEVELOPING THE WEB SITE}

It took several types of professionals to get the web site going. Deborah Smith, the principal investigator of the grant, is responsible for the overall success of the web site. She chose the spectrum of

Deborah K.Smith (dsmith@whoi.edu) is Senior Scientist, Woods Hole Oceanographic Institution, Woods Hole, MA, USA. Edwin Schiele is a freelance science writer in Cambridge, NY, USA. Lori Dolby is Web and Publications Coordinator, Sea Education Association, Falmouth, MA, USA. 


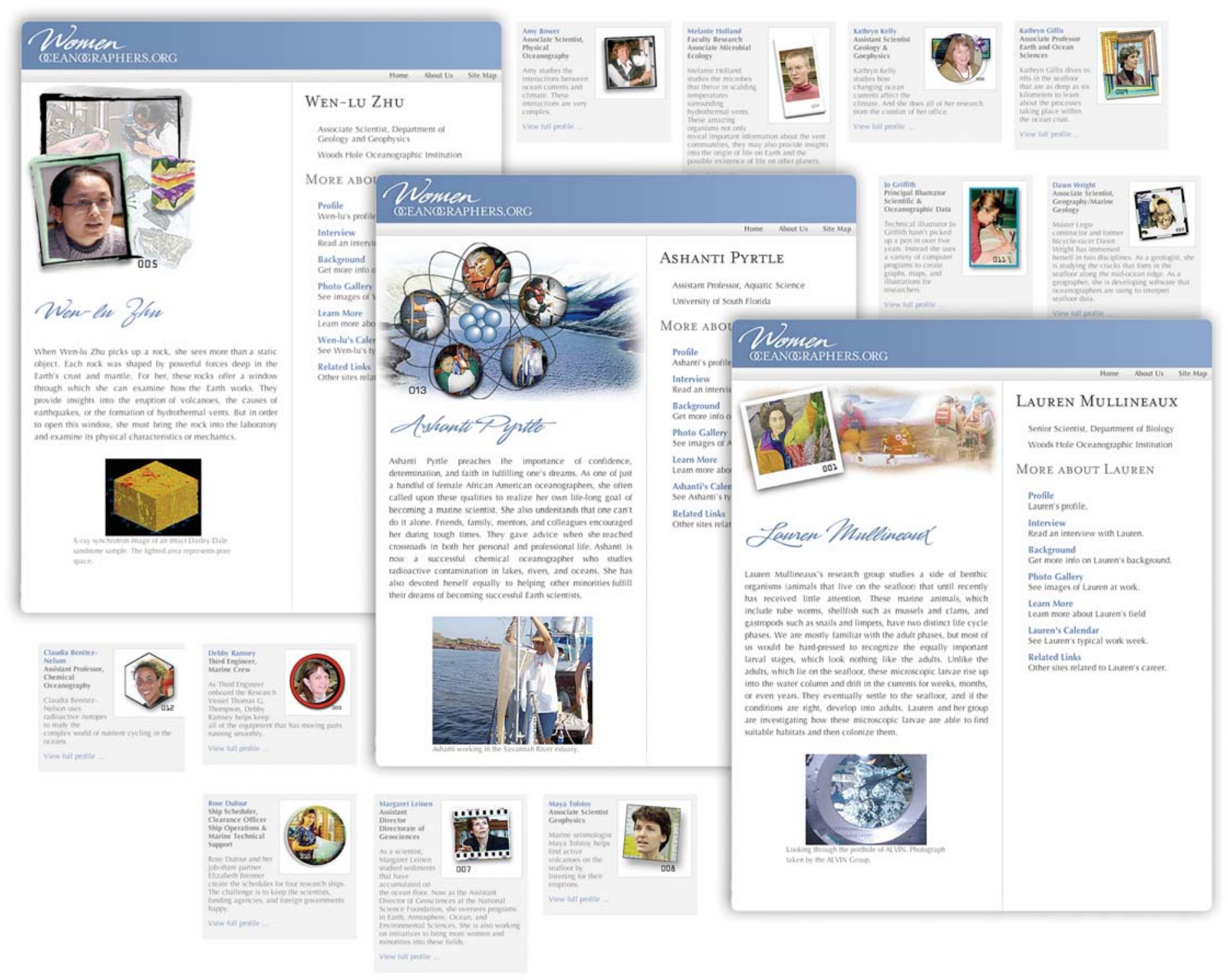

oceanography sub-disciplines it would cover, and then identified and contacted the women about participating in the project. Debbie also wrote the "Learn More" pages, which provide more details on the women's fields of investigation.

Edwin Schiele, a freelance science writer, interviewed the women selected and wrote their stories. Lori Dolby, the "web master," videotaped the interviews, took many photographs, uploaded the information to the web site, and made sure it operated smoothly.

At the beginning of the project, we contacted a web graphic designer because we had neither the confidence nor the skills necessary to design the look and feel of the web site and the navigation scheme that we wanted. That process took several months to sort out. We then started contacting the women we wanted to profile.

Each profile includes an introduction describing the work each woman does, a question and answer interview in which each woman discusses how she progressed through her career, photographs, a background lesson, a calendar section in which each woman chronicles a typical work week, a Curriculum Vita, 
and additional links related to each woman's profession.

After Debbie arranged the logistics of the interview, Edwin sent each woman a list of questions we planned to ask. The interviews generally lasted about two hours. First, we discussed the research or other work each woman was engaged in, then we moved to the question and answer portion. Lori videotaped the entire interview. We initially posted the video of the question and answer portion on the web site in RealPlayer and Windows Media. However, we found that these videos were too unwieldy, so the later profiles only included excerpts of the videos.

After the interviews, Edwin wrote the introduction and edited the question and answers. Debbie wrote the "Learn More" pages with background lessons. The profiled women provided some photographs, wrote the weekly calendars, and provided links to noteworthy publications and relevant web sites. Lori posted everything on the web and addressed problems that popped up. Each woman had a chance to review the introduction and question and answer sections and comment on their accuracy and appropriateness.

One of the most rewarding aspects about the experience has been without exception that each woman featured was extremely cooperative and generous with her time. All of the women shared our goal of making the web site a worthwhile, entertaining, and educational experience for its users.

\section{WEB SITE CONTENT}

In choosing women to profile, we wanted to expose readers to a wide variety of careers in oceanography, including career possibilities that might not oc- cur to everybody. The scientists profiled featured marine geologists, physical oceanographers, chemical oceanographers, and marine biologists, who studied a range of topics and had different approaches to their work. For example, some scientists spent significant time on cruises or dived in submarines to their research sites, while others rarely set foot on a ship and mostly worked in laboratories or on computers. We also chose to include women whose careers were not oriented towards research. We profiled a ship engineer, a ship scheduler, a technical artist, and a high-level administrator at the National Science Foundation.

An introduction appears on the opening page of each profile and describes the work each woman is engaged in. The text and content of the web site targets high school and college students who have some science background. Some of the research described in the profiles is quite specialized and on the surface not especially glamorous. For that reason, we made an effort to convey each woman's excitement about her work, explain why her work is important, and show how her investigations contribute to the understanding of larger questions such as global warming, the structure of ecosystems, and Earth's inner workings. For example, in Wen-lu Zhu's profile, we learn how her investigation of the porosity of rocks found in the deep ocean can teach us about the dynamics of hydrothermal vents. And we learn how Claudia Benitez-Nelson's attempts to unravel the phosphorous cycle may provide insights both into the ocean's ecosystems and climate change. We also stress the important roles that the nonresearch oriented women profiled on the web site play in shaping our understanding of Earth and its oceans. For example, we learn how scientists rely on graphic artists such as Jo Griffith to make sense of and communicate the information these scientists gather. In addition, we learn how the successful juggling of ship schedules and other behind-the-scenes work that Rose Dufour and Elizabeth Brenner perform is critical to the success of all research cruises.

Web site users interested in finding more information about a particular field can read the "Learn More" feature. Or they can click on links provided in the profiles to noteworthy articles chosen by each woman and links to related web sites.

The question-and-answer sections examine the backgrounds and motivations of the women. These sections include discussions of each woman's interests as she was growing up, the reasons each decided to pursue careers in oceanography, the paths each took, the challenges each faced, and the aspects of their work that continue to inspire them. These interviews provide practical advice for women interested in pursuing careers in oceanography. But most interesting of all, they demonstrate that there is no profile one must fit or path one must take when pursuing a career in marine science. While most of the women we profiled became curious about the natural world when they were kids, many didn't decide to pursue a career in oceanography until college or beyond. Some took detours. For example, Kathryn Kelly worked as a car mechanic for five years before pursuing her degree. Debby Ramsey got her doctorate in atmospheric science before switching gears and be- 
coming a ship engineer. Other women's jobs and interests evolved. Margaret Leinen went from scientist to administrator. Dawn Wright started out studying mid-ocean ridges, but has since become an expert in developing GIS software.

Because most of the careers these women have chosen are traditionally male-dominated, we asked each woman whether she had faced any particular challenges based on her gender. Again their answers varied. Some responded that it rarely registered as a major issue. Others cited issues based on the lack of women role models, the challenges of fitting into a male-oriented culture, and the pressure to prove themselves to both their colleagues and to themselves. As an African American, Ashanti Pyrtle said she felt enormous pressure to succeed on behalf of all African American women. Most of the women recalled incidences of patronizing behavior and other slights, such as being mistaken for a secretary at a meeting. Some of the women encountered skepticism and even hostility from colleagues. Many of the women offered advice on how to overcome these obstacles and credited supportive advisors and colleagues for helping them through. Most also agreed that the climate for women is improving.

Those women with kids also discussed the challenge of balancing work and family and offered strategies for handling these pressures. All agreed that it is not for the faint-hearted. Some share child-rearing duties with their husbands. Claudia Benitez-Nelson didn't hesitate to haul her son into work and meetings. Ship schedulers Rose Dufour and Elizabeth Brenner worked out a job-sharing arrangement at Scripps so they could devote more time to their families.

Finally, we wanted to provide readers with a glimpse of the day-to-day routines and demonstrate that there is life outside science for these women. Through the interviews, we learned that these women had a number of outside interests, including acting, dancing, mountain biking, baseball, art, church, and Legos. One of the most popular features of the web site is the calendar chronicling a typical workweek. The lack of glamour makes these calendars especially compelling. Large portions of the day are spent answering e-mail, preparing for lectures, and writing proposals and manuscripts. We also learned about the routines that help these women get through the day from cooking to walking the dog to checking out the window for dolphins and manatees.

\section{RESPONSE TO THE WEB SITE}

One of the biggest challenges was publicizing the web site once it was up. We contacted a number of organizations and urged them to add links to the web site from their web sites. In March 2000, the American Geophysical Union's Eos Transactions published a favorable review of the web site, doubling the traffic in the days following publication. In June 2000, the web site won the San Francisco Exploratorium's “Ten Cool Sites Award” for educational excellence.

Based on web statistics, we know that much of our traffic comes through the Woods Hole Oceanographic Institution's home page, the Stanford University marine web site, and other school web sites. The top Google search phrases leading to the web site include women scientists, oceanographers, marine biologists, oceans, and oceanography. The women we profiled also have referred potential graduate students to the web site.

Although we can infer that many of the people entering the web site are interested in oceanography, we have no way of determining what percentage are students, teachers, scientists, or interested members of the general public. Nor do we have any quantitative measure of whether the web site has influenced any students. However, we do hear anecdotally from men and women scientists that they visit the web site regularly. In particular, they read the weekly calendars to see how colleagues balance their time.

\section{FUTURE}

We initially planned to profile 12 women over the course of one year. However, the web site has proved so successful and we enjoy doing it so much that we are entering our fifth year. As might be expected, we completely underestimated the amount of time needed to make the web site a success. The enthusiasm of the women we have profiled and the satisfaction obtained from profiling the different stories and successes makes it all worthwhile.

Recently, we obtained a supplement to our original grant to redesign the web site to make it accessible to people with disabilities (Section 508 compliancy, see http://www.section508.gov for more details). These changes will help ensure that people with vision impairments who use assistive products such as screen readers and Braille displays can use the web site. At the time of this writing, we are well along with the redesign and look forward to many more years of highlighting the careers of women in oceanography. ⿷匚 